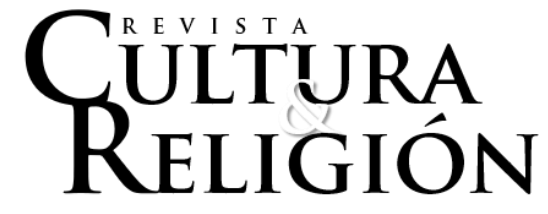

Vol. XV, $\mathrm{N}^{\circ} 1$ (2021) pp. 108-143

Recibido: 22 de noviembre, 2020

Aceptado: 15 de enero, 2021

\title{
DISCURSO FEMINISTA COLOMBIANO PREILUSTRADO: LA IMAGEN FEMENINA EN LA VIDA DE SOR FRANCISCA DE LA CONCEPCIÓN*
}

Feminist discourse previous to the enlightenment: the female image in VIDA by Francisca de la Concepción

\author{
Patricia Fernández Martín ** \\ Universidad Autónoma de Madrid, España
}

ORCID 0000-0003-4112-5507

\section{Resumen}

El objetivo del presente trabajo es demostrar la existencia de un discurso feminista anterior al feminismo euro-norteamericano ilustrado, en un afán por defender que la ideología patriarcal dominante ha contado siempre con una ideología feminista dominada que, por diversos motivos sociohistóricos, no podía hacerse presente de forma explícita en los discursos de las mujeres, especialmente de las religiosas. Para ello, dividimos el texto en tres partes: en la primera ofrecemos ciertas cuestiones teóricas centradas en los estereotipos femeninos defendidos por el patriarcado durante siglos y en el concepto de "ideología" de Verschueren (esto es, el conjunto subyacente de pautas de significado, marcos de interpretación, visiones del mundo o formas de pensamiento y explicación del día a día), de donde se puede desprender el de "ideología de género"; en la segunda parte analizamos el papel de las mujeres 
en la autobiografía de Francisca Josefa de Castillo; y en la tercera ofrecemos una serie de interpretaciones de su discurso que intentan crear vínculos con el contexto sociocultural en que se desarrolló su vida y su obra. La principal conclusión defiende que, mediante un fenómeno lingüístico que se puede llamar "etiquetación dinámica por proximidad emocional", emplea un criterio de clasificación de las mujeres basado en la confianza, siempre cambiante, que le sirve para tomar decisiones en el futuro, pero que en ningún modo impone con motivos excluyentes.

Palabras clave: Francisca Josefa de Castillo, ideología, contexto sociocultural, (auto)imagen femenina, análisis del discurso.

\section{Abstract}

The aim of the paper is to show the existence of a feminist discourse previous to Euro-North-American enlightened feminism, in an effort to defend that the dominant patriarchal ideology has always had a dominated feminist ideology that, for several sociohistorical reasons, could not be explicitly exposed in the texts written by women - especially nuns. Thus, we divide the text into three parts: in the first one, we offer certain theoretical questions focused on the female stereotypes defended by patriarchy for centuries and the concept of "ideology" by Verschueren (an underlying set of guidelines with meaning, schemas of interpretation, visions of the world or ways of thinking and explaining the dairy life), from which the "gender ideology" can be deduced; in the second part, we analyze the role played by women in the autobiography composed by Francisca Josefa de Castillo; and finally, some interpretations of her speech which try to create links with the sociocultural context in which her life and work took place are explained. The main conclusion argues that, through a linguistic phenomenon that might be called "dynamic labeling by emotional proximity", she applies a criterion to classify women based on trust, which helps her make decisions in the future, but which she in no way imposes on anyone with exclusive reasons.

Revista Cultura \& Religión Vol. XV, 2021 № 1 (enero-junio) 
Keywords: ideología, contexto sociocultural, (auto)imagen femenina, análisis del discurso.

\section{Introducción}

Si hubiera que elegir dos elementos para caracterizar la época colonial en que se inserta contextualmente este trabajo, concretamente la coincidente con la biografía de una religiosa como sor Francisca de la Concepción (16711742), dichos elementos serían el armazón político contrarreformista que se llevaba aplicando desde mediados del siglo XVI al proceso de evangelización en América y la pirámide sociológica sobre la que se construye en Indias todo un sistema de relaciones jerárquicas de poder (Pérez Herrero, 2011; Martínez Shaw y Alfonso Mola, 2008). Ambos aspectos, naturalmente, suponían considerar inferiores a las mujeres (Bernabé Ubieta, 2016), pues los principios supuestamente basados en la religión cristiana "las consideraban seres débiles, carentes de fortaleza de ánimo y que por tanto debían ser protegidas tanto física como moralmente" (Chocano Mena, 2000, p. 70), sin que esto dejase de conllevar una categorización sociológica que, dentro de la jerarquía social propiamente femenina, implicaba que

la mujer blanca, castellana, o en su defecto criolla [como Francisca], se sitúa en el vértice de una pirámide de prestigio, donde la india de linaje noble ocupa un segundo escalón, al que le sigue la mestiza y luego la mulata, para dejar en la base de esa pirámide a aquella que se considera siempre inferior, la negra. (Ferrús y Girona, 2009, p. 10). ${ }^{1}$

Simultáneamente, si estos dos aspectos se fusionan en uno solo, de manera que se tratan como elementos principales de la ideología sociocultural ${ }^{2}$

\footnotetext{
${ }^{1}$ Estos términos, que empleamos más adelante fuera de cita, corresponden a la clasificación patriarcal de la época colonial, no a la de la autora del presente artículo en la actualidad.

${ }^{2}$ Usamos siempre el término "sociocultural", en lugar de "social" o "cultural", separadamente, porque, siguiendo el concepto de cultura de Díaz de Rada (2010) y asumiendo el fracaso implícito de su separación (Kuper, 2001), no consideramos pertinente para nuestros objetivos distinguir los elementos sociales de los elementos culturales, pues ambas categorías analíticas 
del momento (dicha pirámide como esencia de la estructura social de un lugar y el cristianismo con fines políticos como particularidad cultural de una época), puede asumirse la existencia de escritos en los que de forma tácita se muestre un velado descontento con dicha ideología, especialmente en lo referido al papel desempeñado por las mujeres que no eran tan libres como los hombres a la hora de componer sus textos ${ }^{3}$ (Bernabé Ubieta, 2016; Fernández Martín, 2020).

En efecto, textos autobiográficos como los de Catalina de Siena, Teresa de Ávila o la misma Francisca Josefa de Castillo, generalmente tildados de "literatura espiritual y devocional" (Ramón, 2010, p. 157), en realidad no constituyen excepción alguna, pues su categorización discursiva como literatura mística veta la posibilidad de que puedan pertenecer textualmente a otras áreas del saber de mayor prestigio sociocultural, como la filosofía o la teología, a las que no se les permite pertenecer por ser, precisamente, femeninos (Chocano Mena, 2000; Fernández Martín, 2020; Ferrús Antón, 2008; Forcades i Vila, 2011; Herrera, 2017; Llamedo González, 2018; Lewandowska, 2013; Walton, 2004). ${ }^{4}$ A la larga, esta categorización excluyente oculta la lucha de poder que se esconde tras la ideología de género, que forma parte de los valores socioculturales que, circularmente, determinan qué práctica discursiva tiene prestigio y cuál carece de él (Servén Díez, 2008; Steffanell, 2010).

En otras palabras, al haber sido clasificadas dentro de géneros textuales poco prestigiosos (Ferrús y Girona, 2009), las prácticas discursivas femeninas han sido en general poco exploradas, por lo que no se conocen lo suficiente

se encuentran perfectamente imbricadas en las prácticas humanas, que es como entendemos el producto discursivo objeto de nuestro análisis.

${ }^{3}$ En este trabajo tomamos "discurso" y "texto" como sinónimos, en un sentido coseriano que, en esencia, alude a su configuración como producto lingüístico producido por un hablante concreto en una situación determinada para un interlocutor específico (Coseriu, 2007).

${ }^{4}$ Recuérdese "la problemática que desde el Índice de Valdés (1559) vivía la mística castellana, censurada casi al completo, que ahora encuentra su espacio de desarrollo al sustituir enseñanza por vivencia, al circunscribir su sentido a la experiencia singular y alejarlo de cualquier pretensión teológica" (Ferrús Antón, 2008, p. 33). Este conocimiento sociocultural compartido puede ser clave para entender el imaginario colectivo al que se tenían que enfrentar las escritoras áureas que desearan escribir textos teológicos o filosóficos que se salieran de lo discursivamente establecido como "místico".

Revista Cultura \& Religión Vol. XV, 2021 No 1 (enero-junio)

Fernández M., P. (2021). Discurso feminista colombiano preilustrado: la imagen femenina en la vida de sor Francisca de la Concepción. Revista Cultura \& Religión, $15(1), 108-143$ 
para saber no solo qué pensaba la mujer de sí misma, sino también cómo se posicionaba sociopolíticamente dentro de la sociedad patriarcal en que le había tocado vivir (Sánchez Díaz Aldagalán, 2019). Una forma de luchar contra este desconocimiento, sin embargo, es asumir que muchas escritoras se encuentran a caballo entre la obediencia y la subversión al discurso-confesor (Arévalo Viveros, 2017; Ferrús Antón, 2008), lo que supone que estas mujeres podían dejar por escrito (consciente o inconscientemente) ciertos mensajes contrarios a la ideología patriarcal dominante, en lo que podría tratarse de un discurso feminista casi invisible. Emplear "casi”" implica asumir que es posible encontrar discursos feministas anteriores a la Revolución Francesa, si bien hay que comprenderlos dentro de un contexto sociohistórico en el que la cosmovisión cristiana, determinada esencialmente por la teología oficial, se erige en configuración hegemónica del hecho social y, por tanto, no pueden ser todo lo explícitos que sin duda alguna serán siglos después. Resulta esencial, pues, no solo mantener metodológicamente vivo el concepto de "ideología" sino asumir que, en este caso más que en otros muchos, esta ha de mostrarse de forma tácita.

Efectivamente, dentro de la historia del feminismo como movimiento político y, por tanto, inserto en un determinado contexto sociocultural, la primera ola tiene lugar gracias en parte a la conjunción sucedida entre la epistemología cartesiana, las ideas ilustradas como inicio del proceso deslegitimador del patriarcado y la Revolución Francesa como situación sociohistórica determinante (Amorós Puente, 2008; Stamile, 2020; Valcárcel, 2010). Esta interrelación de factores facilita que las "memorias de agravios" medievales de los textos de Christine de Pizan e Isabel de Villena, entre otras, y algunos discursos renacentistas y barrocos como los de Teresa de Cepeda y Ahumada, María de San José Salazar, María de Zayas, María de Jesús de Ágreda, sor Juana Inés de la Cruz, Mary Astell y Elena Cornaro Piscopia (Arévalo Viveros, 2017; Bueno-Gómez, 2018, 2019; Fernández Martín, 2020; Ferrús Antón, 2008; Forcades i Vila, 2011; Manero Sorolla, 1992; Noguerol, 2002; Valcárcel, 2010), se conviertan en verdaderas vindicaciones de la mano 
de las que se tienden a considerar canónicamente las fundadoras del feminismo, Olympe de Gouges y Mary Wollstonecraft, ya a las puertas del siglo XIX (Amorós Puente, 2008; Amorós y De Miguel Álvarez, 2007; Stamile, 2020). Resulta, entonces, evidente que a las mujeres preilustradas, precartesianas y prerrevolucionarias "les faltan las condiciones histórico-sociales y los correspondientes instrumentos simbólicos y teóricos para poner en cuestión las bases mismas de la legitimidad del poder patriarcal", para lo cual tendrán que esperar "a la influencia social de los principios de la filosofía de Descartes, de las teorías del contrato social así como a las Revoluciones francesa y americana (sic)" (Amorós Puente, 2008, p. 70).

Simplificando mucho, podría defenderse que a esta primera ola de feminismo de la igualdad, que busca sobre todo "eliminar todas las formas de discriminación entre hombres y mujeres basadas en razón de sexo" (Stamile, 2020, p. 13), se le añade un siglo después una segunda ola a caballo entre la igualdad y la diferencia, que pretende cuestionar el concepto mismo de igualdad dentro del aparentemente único modelo de justicia liberal, sin el cual, como hemos visto, no puede entenderse el feminismo en Occidente (Amorós Puente, 2008; Valcárcel, 2010). Ya a mediados del siglo XX, la tercera ola de feminismo propugna "garantizar el acceso a las mujeres en contextos considerados típicamente masculinos, [...] es decir, en todos los lugares en los que las mujeres por su propia naturaleza estaban consideradas poco aptas para las tareas políticas y económicas fuera del hogar" (Stamile, 2020, p. 20), sin que por ello pierdan su identidad femenina, es decir, sin que por este motivo sean consideradas "menos mujeres".

El objetivo, pues, del presente trabajo es demostrar la existencia de un discurso feminista anterior al inicio del feminismo canónico occidental (entendido aquí como euronorteamericano), en un afán por defender que la ideología de género dominante (patriarcal) ha contado siempre con una ideología de género dominada (feminista) que, por diversos motivos sociohistóricos, no podía hacerse presente de forma explícita ni en la forma de vida ni, naturalmente, en los discursos de las mujeres (Chocano Mena, 2000). 
Así, entendemos que hay numerosas gotas de feminismo en los textos escritos por mujeres a lo largo de la historia, expresadas de forma velada y empleando estrategias discursivas como la (des)autorización, el autodesprecio o la autoestigmatización (Arévalo Viveros, 2017; Bernabé Ubieta, 2016; Cortés Timoner, 2017). Para alcanzar dicho propósito, se analiza la tipología de mujeres que aparecen en el texto autobiográfico de Francisca Josefa de Castillo (1671-1742), con la intención a su vez de romper los estereotipos heredados del patriarcado (de uso no exclusivo de los hombres) que las clasifican, esencialmente, ${ }^{5}$ en santas (o místicas), brujas, putas y tontas (Bechtel, 2001; Bernabé Ubieta, 2016), y que llega, a su modo, a la actualidad (Fogelman, 2014; González Marín, 2003; Hincapié, 2007; Sánchez Díaz Aldagalán, 2019).

Hemos seleccionado dicho texto por varios motivos. En primer lugar, es un texto considerado preilustrado, de acuerdo con la tradicional temporalización de la historia de la literatura hispanoamericana (Oviedo, 2012, apartado 6.5) y, en cualquier caso, es anterior a la expansión del pensamiento cartesiano y a la Revolución Francesa, el momento histórico que suele asociarse con el origen canónico del feminismo (Amorós Puente, 2008; Amorós y De Miguel Álvarez, 2007; Stamile, 2020). En segundo lugar, es una escritora cuyos rasgos socioculturales parecen ser en todo opuestos a los de quienes mantienen el poder absoluto de la época, inserta todavía en el Antiguo Régimen, pues es mujer, religiosa y americana. En tercer lugar, Francisca Josefa es coetánea a la escuela del derecho natural racionalista, época que se ha dado en llamar "primera generación de derechos humanos", dentro de la historia de los derechos fundamentales (Puleo, 2008), lo que puede implicar que respirase en el ambiente sociocultural de su época cierta necesidad de reivindicar la igualdad entre hombres y mujeres o, cuando menos, de planteársela basándose en la teología oficial, de forma similar a como lo hace por la misma época la también

5 En este trabajo utilizamos estas cuatro simplistas y reduccionistas categorías por las exigencias metodológicas del mismo texto analizado, aunque somos conscientes de que hay otras categorías igualmente opresivas que también se han aplicado para controlar a las mujeres, como las de presas, locas y, naturalmente, madresposas (Lagarde y de los Ríos, 2003).

Revista Cultura \& Religión Vol. XV, 2021 № 1 (enero-junio) femenina en la vida de sor Francisca de la Concepción. Revista Cultura \& Religión, $15(1), 108-143$ 
americana sor Juana Inés de la Cruz (Brescia, 1998; Chocano Mena, 2000). Y, en cuarto lugar, su atenta lectura deja entrever, en ocasiones, un discurso feminista presente probablemente en otras muchas mujeres anteriores a la Revolución Francesa (Bueno-Gómez, 2018, 2019; Fernández Martín, 2020), en el que, de forma implícita, defiende un papel sociocultural de la mujer que rompe con las expectativas que el hombre se hace de ella en su propia sociedad.

Dividimos para ello el artículo en tres partes: en la primera ofrecemos ciertas cuestiones teóricas que nos sirven de base para el análisis (apartado 1); en la segunda analizamos el papel de las mujeres en la autobiografía de la mencionada Francisca Josefa de Castillo (apartado 2); y en la tercera ofrecemos una serie de interpretaciones de su discurso que intentan crear vínculos con el contexto sociocultural en que se desarrolló su vida y su obra (apartado 3).

\section{Cuestiones teóricas: estereotipos femeninos e ideología de género}

Como se ha dejado entrever anteriormente, el trabajo versa en torno a dos conceptos teóricos íntimamente relacionados: la ideología de género y la configuración que de la mujer se ha construido en el imaginario colectivo patriarcal, dentro de la tradición judeocristiana, reducida, en general, a las cuatro grandes categorías de puta, bruja, tonta y santa (Bechtel, 2001; Bernabé Ubieta, 2016; Lagarde y de los Ríos, 2003).

El primer concepto, la ideología de género, es en tanto ideología el conjunto subyacente de pautas de significado, marcos de interpretación, visiones del mundo o formas de pensamiento y explicación del día a día que, integradas sociocognitivamente, implican relaciones de poder incuestionadas que buscan naturalizar la diferencia en el trato entre hombres y mujeres, a través de un proceso de construcción simbólica que permite que se acaben asumiendo como normales. Entendemos por "normal", claro está, lo que se ha convertido en norma a modo de hábitus bourdienano, estructura estructurante hecha estructura estructurada (Bourdieu, 2008; Verschueren, 2013).

Como consecuencia, la categoría de género es empleada como categoría analítica que marca "la interrelación entre la distinción sexual genital, las 
construcciones sociales y la asignación de modos de autoconcebirse, de ser y de estar en el mundo" (Robles Rivera, 2018, p. 66), es decir, es el "doblete entre la diferencia biológica, natural, que se solidifica volviéndose diferencia normativa [social]" (Valcárcel, 2010, pp. 466-467). La tradición, apoyada en la ideología de género dominante, ha indicado que sea la masculinidad el modelo por antonomasia empleado para establecer pautas de comportamiento guiadas por concepciones universalizadoras de la realidad particular. Sin embargo, el hecho en sí mismo de que haya personas, a lo largo de los siglos, que se hayan percatado de que "lo aceptado de forma socio-política no necesariamente ha de ser aceptable de forma ético-política" (Ródenas Utray, 2008, p. 165) hace pensar que, aunque la ideología dominante sea mayoritaria en cada momento, siempre hay contraideologías que, expresadas por personas concretas, diacrónicamente conforman un todo conjunto sociocognitivamente integrado. Estas contraideologías, tal vez poco significativas cuantitativamente, son cruciales para comprender la esencia de las rebeliones discursivas (pues difícil era que las hubiera de otro modo; Lewellen, 2003) cualitativamente.

En el caso de las mujeres, son los pequeños mensajes de corte típicamente feminista los que a lo largo de la historia se han manifestado contra la ideología de género hegemónica. En concreto, puede entenderse que la tan manida (y evidentemente errónea) reducción del ser femenino a una tipología de cuatro (o más) categorías ha sido constantemente criticada por las propias mujeres a las que, sin embargo, no se les ha dado voz para justificar el motivo del error de semejante reduccionismo, pues, como se ha señalado en la introducción, ha habido también una tendencia a invisibilizar sus discursos o a etiquetarlos dentro de disciplinas epistemológicas de escaso prestigio sociocultural (Bernabé Ubieta, 2016; Fernández Martín, 2020; Lagarde y de los Ríos, 2003; Martínez Cano, 2016).

En otras palabras, la etiquetación esencialmente patriarcal que se ha llevado a cabo de las mujeres sirve para marcar "a un colectivo cuyo comportamiento incomoda, cuestiona o produce zozobra" (Bernabé Ubieta, 2016, p. 263), que pasa a ser evaluado en función del referente, entendido, 
entonces, de manera homogeneizada, como la única alternativa posible, tras un proceso sociocultural de naturalización en el que la ideología (en nuestro caso, de género) desempeña un papel esencial (González Marín, 2003). El feminismo se concibe en este trabajo, pues, como cualquier ruptura ideológica y, por tanto, tácita, que se produzca mediante el discurso de la reduccionista etiquetación de la imagen femenina que se base en las cuatro categorías indicadas (Bechtel, 2001; Bernabé Ubieta, 2016) ${ }^{6}$ o en otras cualesquiera igualmente simplistas (Hincapié, 2007; Lagarde y de los Ríos, 2003).

\section{Análisis del discurso autobiográfico de sor Francisca Josefa de Castillo}

Francisca Josefa de Castillo y Guevara nace en octubre de 1671, hija de doña María Guevara Niño y Rojas, natural de Tunja (Nuevo Reino de Granada, hoy Colombia) y de don Francisco Ventura de Castillo y Toledo, procedente de Illescas (Toledo, España). Desde muy niña muestra una profunda melancolía que acaba permitiéndole profesar en el Real Convento de santa Clara de Tunja en 1689 como Francisca de la Concepción, donde desarrolla diversas actividades (sacristana, portera, enfermera, maestra de novicias, secretaria e incluso abadesa) hasta su muerte, ocurrida en 1742. Además de su Vida, que analizamos aquí, escribió otros textos como Afectos espirituales, en los que plasma su experiencia mística, y una serie de poemas (Arévalo Viveros, 2017; Galaz-Vivar Welden, 1990; Herrera, 2017; Steffanell, 2010).

El discurso autobiográfico de Francisca Josefa de Castillo que estudiamos a continuación se presta con facilidad para una lectura que huye de

${ }^{6}$ Dicha ruptura es necesariamente tácita porque las páginas de una autobiografía femenina, como probablemente las de otros muchos tipos de texto (Verschueren, 2013), contienen mucha más información de lo que en ellas se expone de forma explícita (Arévalo Viveros, 2017; Bueno-Gómez, 2018, 2019; Fernández Martín, 2020; Ferrús Antón, 2008; Forcades i Vila, 2011; Lewandowska, 2013, 2019; Noguerol, 2002; Valcárcel, 2010). Recuérdese que cuando la mexicana sor Juana Inés de la Cruz (cuyos textos Francisca Josefa conocía bien; Galaz-Vivar Welden, 1990) defiende lo significativo del silencio, viene a implicar que no es necesario poner por escrito aquello que todo el mundo da por hecho: "[Juan el evangelista] No dice lo que vio, pero dice que no lo puede decir, de manera que aquellas cosas que no se pueden decir es menester decir siquiera que no se pueden decir, para que se entienda que al callar no es no haber qué decir sino no caber en las voces lo mucho que hay que decir" (De la Cruz, [1692] 1994, líneas 78-83, p. 451).

Revista Cultura \& Religión Vol. XV, 2021 № 1 (enero-junio) femenina en la vida de sor Francisca de la Concepción. Revista Cultura \& Religión, $15(1), 108-143$ 
la superficie del tópico, pues a través de ciertas palabras sabiamente colocadas en determinados puntos del texto deja entrever, en el contenido filosóficoteológico, su manera de comprender el mundo a la vez que indica, en la forma del discurso autobiográfico, que no puede ser más explícita (Noguerol, 2002). Metodológicamente, se adopta una perspectiva intertextual que nos permite ir más allá de las simples apariencias, partiendo, naturalmente, de una base teológica y filosófica que aspira a ser útil para comprender el universo discursivo en que se mueve la escritora (Galaz-Vivar Welden, 1990; Herrera, 2017), pues, como se ha señalado, se busca descubrir la manera en que interactúa lo implícito con lo explícito (Verschueren, 2013). Por último, las mujeres que aparecen en la autobiografía estudiada y en cuyo análisis nos detenemos a continuación son la Virgen María (apartado 2.1), algunas santas (apartado 2.2), su madre (apartado 2.3), ciertas religiosas y criadas con las que convive en el convento (apartado 2.4) y ella misma (apartado 2.5).

\section{La Virgen María}

El papel desempeñado por la Virgen María en los discursos femeninos cristianos está aún por explorar, pues es posible que, en ellos, más allá de su función de intermediaria entre lo terrenal y lo celestial, la figura simbólica de María de Nazaret demuestre fehacientemente la innecesaria aparición del varón para culminar lo que tradicionalmente se ha considerado su esencia: la maternidad. En María la relación mujer-Dios es tan estrecha que se puede convertir en una contundente prueba de la irrelevancia masculina en la cosmovisión cristiana (Beattie, 2004). ${ }^{7}$

Sor Francisca Josefa de Castillo es perfectamente consciente de este poder mariano (Herrera, 2017), aunque no puede expresarlo de manera explícita. De ahí que sea interesante resaltar, en primer lugar, su empleo como miembro familiar de referencia cuando se dirige al mismo Jesús ("Valedme vos,

${ }^{7}$ Como de hecho demuestran los problemas que tuvo con la Inquisición, en vida, la también franciscana María de Jesús de Ágreda y la censura que sufrió, ya póstumamente, su obra Mística ciudad de Dios, en la que la Virgen se refiere a Jesús como "Hijo de Dios y mío" (Ferrús Antón, 2008; Forcades i Vila, 2011, p. 81).

Revista Cultura \& Religión Vol. XV, 2021 № 1 (enero-junio) 
dulcísimo Jesús, hijo de María, verdadera vida de mi corazón”, p. 266 ${ }^{8}$, simulando lo que habitualmente se ha efectuado con las fórmulas de tratamiento de hombres y mujeres, en las que, como es sabido, a ellas ("señora", "señorita") se las conocía siempre por sus relaciones con ellos ("señor") y nunca a la inversa.

En segundo lugar, la clarisa sabe también que el poder de María es mucho más de lo que el patriarcado eclesiástico ha dado a entender a lo largo de la historia, pues es con su consentimiento con lo que comienza verdaderamente el cristianismo ("hágase en mí según Tu palabra"). Este discurso tan poderoso la convierte en la original vía de salvación: "pedíalo así continuamente a la Madre y puerta de todo el bien, mi Señora la Virgen María" (p. 271).

Lo más habitual, no obstante, es, en tercer lugar, que esta función soteriológica sea desempeñada por María como puente metafísico entre Jesús y ella (ver cita 1): "También conocí cuánto puede la intercesión de la Santísima Virgen para las benditas ánimas" (p. 189). Se asume su figura, pues, de acuerdo con la tradición cristiana, como madre verdadera que perdona todos los pecados (ver cita 2) ("no podía caber devoción a la Virgen Santísima, ni que ella mirara con ojos de madre al alma manchada con tal fealdad", p. 151), lo que la sitúa parcialmente a la misma altura de Cristo (Fogelman, 2014):

1) [...] mas el Santo Ángel de mi guarda debió de favorecerme, porque a lo que me puedo acordar, llamando a Nuestra Señora, a quien yo tenía por madre y llamaba en mis aprietos y necesidades, me salí de la pieza, asustada y temerosa; y así me libró Nuestro Señor de aquel peligro, cuando no me parece que tendría siete años. (pp. 85-86).

2) [...] vi a la Santísima Virgen junto a mí, con un niño recién nacido y muy amable, que poniéndolo en el suelo, me decía: "Mira, este niño ha nacido para ti". Consolóme y esto me dio fuerza, lo que no sabré decir, y el ver que mi señora y Madre Santísima tenía el mismo vestido que solía

\footnotetext{
${ }^{8}$ Los números de página sin cita bibliográfica previa hacen alusión a Vida de sor Francisca de Castillo, según la edición utilizada y reseñada en la lista de referencias bibliográficas al final de este artículo.

Revista Cultura \& Religión Vol. XV, 2021 No 1 (enero-junio) 
traer mi madre natural [...]. ¡Oh, Señora mía, quién pensara que después de tanta inconstancia y yerros míos, te habías de mostrar como madre! (p. 111).

Finalmente, Francisca se dirige a la Virgen cuando pretende reconfortarse, cuando busca un refugio y una paz interior que no puede lograr más que acudiendo a cualesquiera de sus hierofanías, sean imágenes (p. 167), oraciones (pp. 187-188, 190, 199, 240) o algunas de las iglesias dedicadas a ella (p. 318). Parece poder decirse que, cuando pierde el control sobre lo que sucede a su alrededor y no es capaz de encontrar otra solución, la franciscana confía plenamente en otra mujer de la que la separan siglos, pero a la que la une su estrecha fe (Herrera, 2017).

\section{Algunas santas}

Las santas que aparecen en el relato autobiográfico de Francisca son esencialmente cinco, entre las que cobra naturalmente especial importancia santa Clara (pp. 187, 283), a quien le debe la profesión: santa Rosa de Lima, santa Catalina de Siena, santa Teresa de Jesús y santa Magdalena de Pazzi. Rosa es la primera santa americana, lo que la dota de un poder identitario especial, basado en la idea de que "sólo cuando una tierra produce santos se considera madura espiritualmente" (Ferrús y Girona, 2009, p. 24), poder que es traspasado a Francisca en su juventud, cuando toma el hábito dominico en lo que supone una solicitud de favores a la santa (ver cita 3). Catalina, por su parte, a quien contempla directamente en una de sus visiones (ver cita 4), simboliza el origen de la espiritualidad femenina, lo que a su vez supone la libertad del yo para relacionarse con lo divino a su modo, sin restricciones oficiales esencialmente marcadas por el hombre (Ferrús y Girona, 2009):

3) Criábame muy enferma, y esto, y el gran amor que mis padres me tenían, hacía que me miraran con mucho regalo y compasión, y aunque me habían puesto el hábito de Santa Rosa de Lima, que se lo prometieron a la santa porque me diera salud Nuestro Señor, mi madre se esmeraba en

Revista Cultura \& Religión Vol. XV, 2021 No 1 (enero-junio) 
ponerme joyas y aderezos, y yo era querida de toda la casa y gente que asistía a mis padres (p. 87).

4) Veía también que estaban en su compañía muchos santos, en particular conocí a Santa Catalina de Siena, y entendí que aquellas azucenas eran los trabajos que estaba padeciendo, y así volví en mí con mucho consuelo y aliento (p. 140).

La siguiente santa más mencionada en su obra es Teresa de Ávila, que cobra además especial importancia desde una doble perspectiva: como modelo formal literario del género discursivo de la autobiografía (Arévalo Viveros, 2017; Manero Sorolla, 1992; Poutrin, 2018; Walton, 2004), pues su influencia se encuentra a lo largo de toda la obra; y como modelo conceptual de la misma configuración del texto, utilizada un siglo después por determinados varones con motivos nacionalistas, ya que "[u]na manera de establecer la diferencia con España era la publicación de textos místicos que al menos se equipararan con los de Santa Teresa de Jesús en la península ibérica” (Steffanel, 2010, p. 110).

La visión que Francisca ofrece de la filósofa abulense se centra en las dos facetas biográficas en que más se enfrentó al patriarcado, tanto por la política de autogobierno femenino que implicaba la reforma descalza, como por la rebeldía que supone para las mujeres el absoluto alejamiento del varón una vez deciden entrar al convento (Arévalo Viveros, 2017; Fernández Martín, 2020; Ferrús Antón, 2008): como escritora ("Leía mi madre los libros de Santa Teresa de Jesús y sus Fundaciones y a mí me daba un tan gran deseo de ser como una de aquellas monjas que procuraba hacer alguna penitencia”, p. 86) y como religiosa ("porque mi deseo era ser carmelita, pareciéndome que allí no había más que, como la madre Santa Teresa dejó sus conventos, entrar y morir a todo, y vivir para Dios, unidas en caridad", p. 114).

La santa que más aparece, sin embargo, es María Magdalena de Pazzi, cuya autobiografía le sirve como modelo de conducta (ver cita 5), gracias a la importancia de su obra escrita (pp. 101, 185). Más allá de su posible figura como modelo escriturario o comportamental, la figura de Magdalena puede correlacionarse, dentro de la obra de Francisca, con una especie de Ruah, Dios- 
Sofía, con quien padece una profunda fusión mística, la cual, a su vez, supone una visión inclusiva de la práctica religiosa, que busca la renovación de la fe cristiana a partir de la relectura de los Evangelios (Martínez Cano, 2016; Ramón, 2010), en concreto, de lo que entonces implicaría una completa y absolutamente innecesaria lectura masculina del mismo concepto de Dios (ver cita 6), en la línea de lo que la misma clarisa deja entrever sobre la Virgen en su discurso (apartado 2.1):

5) $[\ldots]$ yo recibí con mucho consuelo aquel castigo y penitencia de ir en lugar de lega a la enfermería, porque había leído en la vida de Santa Magdelana de Pasis (a quien con toda mi alma había deseado tomar por maestra), que era muy amante de las enfermas [...] (p. 185).

6) Parecíame que la Santa Magdalena de Pasis, mi madre y mi señora, se llegaba amorosamente a mi alma y se unía su espíritu con el mío, con un abrazo y unión muy estrecha e íntima, alentándome y consolándome (p. 232).

En el caso de las santas, entonces, Francisca Josefa ve una perfecta relación entre lo sagrado y lo profano, pues son mujeres que, habiendo vivido las penas del mundo terrenal (como ella), consiguen acceso directo al mundo celestial, a lo inefable, lo numinoso, lo divino (Fraijó, 1998; Galaz-Vivar Welden, 1990; Martín Velasco, 2006), lo que en la práctica del misterio cristiano, acorde con la idea teresiana subyacente centrada en la humanidad de Jesús ("Yo solo podía pensar en Cristo como hombre", V 9:6), implica entenderlas como a humanas transformadas póstumamente en diosas.

\section{Su madre}

La figura materna de Francisca tiene gran importancia, naturalmente, como origen de su misma persona. A sus ojos de niña, constituye todo un ejemplo de vida religiosa (ver cita 7). Dada la bondad que la caracteriza a lo largo de toda la vida, no merece morir en soledad, por lo que, una vez ha enviudado, la franciscana expone detalladamente tres argumentos para justificar su entrada en el convento: su incapacidad para vivir sola, el permiso de su 
confesor y el mandamiento vetatestamentario de honrar a los padres. Tras una larga enfermedad que le supuso, entre otros, quedarse ciega y "tullida de pies y manos" (p. 139) durante dos años, la madre de Francisca Josefa fallece en una de sus celdas (ver cita 8):

7) Así mismo mi madre era tan temerosa de Dios cuanto amiga de los pobres y enemiga de vanidades, de aliños y entretenimientos; y de tanta humildad, que habiendo enviudado y estando casi ciega, le dio una criada muchos golpes en una iglesia para que se quitara del lugar donde estaba, lo cual llevó con mucha mansedumbre, y se quitó medio arrastrando; y me lo refería alabando a Dios y bendiciéndolo, porque la había traído de tanta estimación a tiempo en que padeciera algo (pp. 83-84).

8) Allí fue Nuestro Señor servido de llevarse para sí a mi madre, habiéndole las religiosas dado el hábito y profesión como se hace en artículo de muerte, y con una disposición admirable, a lo que todos y el religioso que la asistió decían: «Acabó sus trabajos» y empezaron los míos (p. 140).

A lo largo del discurso autobiográfico, la madre de la clarisa es contemplada como una mártir cuya acción en vida recuerda sobremanera a la del mismo Jesús (ver cita 7), como cuando ordena poner la otra mejilla a aquel que hiere en una (La Santa Biblia, Lc 6, 27-31; Mc 5, 38-42), o cuando después de una vida muy dura en la que solo deseaba sacrificarse a Dios, por fin, encuentra la muerte como final del trayecto (ver cita 8).

\section{Religiosas y criadas en el convento}

El grupo de religiosas expuesto por sor Francisca en su autobiografía es probablemente el más numeroso. Dicho grupo permite dos subdivisiones: la primera tiene lugar entre familiares y no familiares de la escritora, de cuyo primer subgrupo cabría destacar a su hermana y a su sobrina Catalina:

9) También se ofreció el que quiso entrar monja mi hermana, que había ya enviudado, y cargó sobre mí un tropel de cosas que fuera largo de decir (p. 221). Luego le dio una enfermedad tan rigurosa, que no solo la postró 
en la cama, mas día y noche, sin cesar, la hacía estar en un continuo gemido como que le despedazaban las entrañas. Era grande la compasión y dolor que yo tenía de verle padecer aquel riguroso dolor, sin poderle hallar ningún alivio, en cuatro meses y medio que duró su enfermedad, hasta que Nuestro Señor se la llevó (p. 236).

10) Pues al cabo de este año y medio que pasé así, me avisaron traían una sobrina mía a ser monja [...]. Pues el día que la trajeron a que la vieran las monjas, yo no vi en ella sino a Nuestro Señor Crucificado; no por ninguna imagen que se representara, sino por un conocimiento del alma, que era como una espada de dos filos que la atravesaba de parte a parte, y me hacía derramar un mar de llanto (pp. 176-177).

Considerado un auténtico clan familiar (pues llegó a tener dentro del convento a su madre, su hermana y seis sobrinas), la escritora da a entender lo inconveniente que le resulta permitir que sus familiares vengan al mismo convento en que ella vive. Así, por una parte, parece querer justificar lo dificultoso de que profesen su sobrina o su hermana, como si realmente fuera algo ajeno por completo a su voluntad (ver citas 9 y 10), al igual que páginas antes ha explicado lo irremediable de que lo haga su madre (apartado 2.3), pero, por otra parte, se observa una diferencia con respecto a la forma en que solicita la entrada en el convento de su sobrina y su hermana (tal vez por motivos generacionales).

En efecto, el hecho de que en el caso de su hermana le baste con indicar como única causa su viudedad, contrasta con la exhaustiva explicación que ha dado para que entre su madre (apartado 2.3), aunque la viudedad de esta no se menciona de forma explícita en ese momento (p. 138), porque se ha explicado en capítulos anteriores. Este vínculo culmina, naturalmente, con la similar manera en que expresa la similitud de sus muertes, sufridas tras dolorosas enfermedades (ver citas 8 y 9). A este respecto, resulta interesante indicar que el concepto del mal -en forma específica de muerte ajena que muestra Francisca- encuentra su consuelo en la resurrección de Jesús. Así, al entender que este se lleva a sus seres queridos, torna su profunda tristeza ("trabajos" [8]), 
soteriológicamente, en la alegría del sacrificio que implica la dicha salvación de Cristo (Granados Valdéz, 2020). Esta esperanza hecha carne le permite, a su vez, asumir la continuación de la vida tras la muerte, en lo que se considera una herencia del judaísmo, donde cabe entender que "la muerte no debería ser el fin de todo, sino la continuación de ese plan previsto por Dios... ¿o el principio, quizás?” (Tapia-Adler, 2007, p. 17). Naturalmente, la necesaria aceptación de la muerte ajena como parte misma de la vida no evita sentir dolor ante este tipo de mal, como bien explica en las Moradas la teóloga abulense: "No penséis que está la cosa en si se muere mi padre o hermano conformarme tanto con la voluntad de Dios que no lo sienta, y si hay trabajos y enfermedades, sufrirlos con contento" (5M 3,7).

Sobre su sobrina, asimismo, resulta destacable que justo el mismo día en que entra en el convento la identifique con Jesucristo (ver cita 10), en un nuevo alarde por poner a determinadas mujeres a su altura (apartados 2.3, 2.5), frente a lo que establecería el canon cristiano masculino, que solo permitía la comparación de la mujer con la Virgen (Hollywood, 2004; Ferrús y Girona, 2009).

Junto a estas parientes, la franciscana vive el día a día con un segundo grupo de mujeres con las que no comparte lazos de sangre y que, quizá por ello, podrían dividirse en "malas", si ella considera que le hacen la vida imposible (ver citas 11-13) y "buenas", según ella las entienda como un apoyo (ver citas 14-16):

11) [...] luego me vino cierta confusión y humillación por medio de una criada que había venido a la celda y haciendo en ella algunos daños, saltó las tapias y se huyó, diciendo afuera cosas de mí, que me fueron de mucha mortificación (p. 193).

12) O porque se cargó con la respuesta o porque ya comunicaba a una monja, se levantó contra mí una persecución tal, que cuando me veían pasar, me escupían, me decían cosas muy sensibles; como eran muchas las amigas y criadas, por todas partes me hallaba acosada y afligida, y más

Revista Cultura \& Religión Vol. XV, 2021 Nº 1 (enero-junio) 
cuando veía mi interior tan lejos de lo que siempre (o el tiempo antes) había pretendido (p. 105).

13) Esta, pues, se había arrimado a mi confesor, como dije, y esto me fue causa de grandes trabajos e inquietudes [...]. Venido que fue, me mandó que le llamara a aquella que digo; yo, mientras las otras se confesaban, la vine a llamar, mas fue soltar una víbora, porque dando gritos y patadas me decía: "Iré, iré sólo a decirle al padre rector quién ella es; hasta aquí he callado, mas ya no, sabrá el padre rector quién es ella, y no volveré más a confesarme con él” (pp. 144-145).

Como puede verse en las citas anteriores, no hay distinción de clase para ser etiquetada de "amiga" o "enemiga" en el discurso de Francisca, pues en la primera cita es una criada la que habla mal de ella, mientras que en la segunda son varias mujeres, monjas y criadas (estas siempre seglares; Martínez Cuesta, 1995), las que parecen tener un comportamiento bastante violento con ella (o con una de sus sobrinas, p. 179). La protagonista de la tercera cita es una religiosa a la que, según la versión de nuestra escritora, ella no ha hecho nada para que se queje de su comportamiento ante el confesor. ${ }^{9}$

Entre las mujeres buenas hay igualmente criadas y religiosas. Aquí se encuentra, sin duda, aquella monja que le cede la celda sin pedirle nada a cambio (pp. 132-133), quienes piden perdón por sus errores (ver cita 14) o quienes, simplemente, se han convertido en sus amigas (pp. 172-173) o en sus compañeras de trabajo (ver cita 15) y quienes la toman como "cabeza de bandos" en los enfrentamientos entre distintas facciones políticas (ver cita 16). ${ }^{10}$

\footnotetext{
${ }^{9}$ Este, por cierto, parece convertirse en numerosas ocasiones en objeto de control de las monjas, especialmente de la abadesa, pues por él pasaba la autoridad de las decisiones que afectaban al convento (Ferrús Antón, 2008). No es de extrañar, entonces, que aparte de los ejemplos narrados con violencia física o verbal (pp. 113, 162-163, 178-179, 195, 261-262), Castillo cuente también algunos episodios en los que el objetivo de sus rivales es convencer a sus superiores (el confesor, la abadesa...) de que hagan lo que ellas estimen oportuno (pp. 158-159, 231), en una lucha por el poder que contradice toda consideración pasiva de la vida conventual (Bernabé Ubieta, 2016; Chocano Mena, 2000; Lewandowska, 2019).

${ }^{10}$ Anecdóticamente, estos enfrentamientos recuerdan, por ejemplo, a los conflictos políticos masculinos que narra la condesa Pardo Bazán en Los pazos de Ulloa siglo y medio después 
14) Algunas criadas vinieron entonces a decirme las perdonara, que habían levantado algunas cosas; y había ocasión de esto, porque ya dije que en este tiempo trataba más con las criaturas, pareciéndome mejor no estar retirada, sola y trabajosa [...] (p. 176).

15) Ayudábame mucho la santa compañía de las dos religiosas que me eran superiores en la portería, en especial la una, que era de grandes virtudes, y aunque no me decía nada, solo su presencia me hacía mucho bien (p. 136).

16) $[\ldots]$ Después se empezó a arder todo en chismes y persecuciones a las que me habían dado su voto, metiendo mano en esto muchos sujetos de fuera y diciéndoles cosas muy pesadas, ellos y las otras religiosas. Ellas venían donde yo estaba a llorar con tanta amargura y aflicción, que no podía yo menos que consolarlas; y de allí se tomó el decir que me hacía cabeza de bandos, que revolvía el convento; y hasta algunas que habían sido mis novicias entraban a la portería donde yo estaba, escupiendo y zapateando, y con otros modos de harto desprecio (p. 252).

Finalmente, cabe señalar que, cuando describe la posibilidad de que algunas monjas estén recibiendo cuestionables visitas en sus celdas, no solo expresa su decepción e incluso su miedo ante tal hecho, sino que además responsabiliza por completo al eclesiástico al que transforma en el demonio, en un acto de rebeldía que recuerda, sin duda, al que constantemente ha hecho el imaginario colectivo masculino con la mujer que no se ha comportado como era de esperar (Bechtel, 2001; Bernabé Ubieta, 2016):

17) Vi pasar el enemigo en hábito de religioso por la puerta de la celda, y que mirando, con unos ojos que daban horror, hacia donde estábamos,

(caps. XXIV-XXVI). La principal diferencia es que, en nuestro caso, Francisca efectúa un liderazgo afectivo fundado en las experiencias vividas que convierten la dimensión emocional en el centro de la relación entre las personas (Mazariegos Herrera, 2019, p. 34), al tomar forma, concretamente, en la confianza generada desde una perspectiva sistémica-compleja. Todo ello nuevamente contribuye a romper las simplistas categorías que se tenían como imagen femenina desde el patriarcado (Bechtel, 2001; Bernabé Ubieta, 2016; Fogelman, 2014; González Marín, 2003; Hincapié, 2007; Lagarde y de los Ríos, 2003; Sánchez Díaz Aldagalán, 2019).

Revista Cultura \& Religión Vol. XV, 2021 Nº 1 (enero-junio) 
se entró en la celda de otra religiosa que estaba junto a la mía; yo no entendí qué sería aquello, mas quedé llena de pavor y tristeza (p. 178).

En síntesis, resulta entonces altamente significativo que, dentro de la cosmovisión cristiana del discurso autobiográfico de Francisca Josefa de Castillo, ciertas mujeres se hagan equivaler de facto a Jesús mientras que algunos hombres se identifiquen con el demonio.

\section{Ella misma}

Cuando se analiza el discurso autobiográfico de Castillo de una forma explícita, lo primero que sale a la luz son las continuas referencias al diablo para definirse a sí misma que ella pone en boca de otros (pp. 114, 119, 123, 202), mujeres (ver cita 18), hombres (ver cita 19) y el mismo diablo (pp. 202, 221-222), en un posible afán por reproducir las críticas establecidas por aquellos no conformes con las decisiones que ella toma. ${ }^{11}$

18) $[. .$.$] una de aquellas religiosas [. .$.$] decía a voces, llena de furor,$ hablando de mí: "Que esa mujer, ese demonio que había entrado en este convento para tanto mal de todas, que desde que ella entró no había paz, que no perdonaba vicarios, ni abadesas, ni hermanas, ni parientes. Ese demonio, decía, a quien con tanto horror he mirado y abominado desde que puso los pies en el convento tan contra mi dictamen y parecer" (pp. 199-200).

19) Pues como llegué a confesarme, comenzó el padre con quien me reconciliaba a decirme que, a todo su entender, yo estaba perdida, ciega del demonio, y que él no quería reconciliarme ni absolverme; y diciendo esto, se levantó del confesionario y me dejó allí (p. 238).

En otras ocasiones, se refugia en el estereotipo de la mujer silenciosa (pp. 84-85, 130, 229) que, por ser de Dios "su pobre esclava, vil y despreciable" (p. 135), puede ser constantemente engañada por un diabólico enemigo. ${ }^{12}$

${ }^{11}$ Recuérdese que siempre se lo ha considerado una figura capaz de articular el desvalimiento de la persona (Cantón, 2009).

${ }^{12}$ Esta estrategia discursiva de autodesprecio recuerda a la llevada a cabo por su correligionaria María de Jesús de Ágreda, que también se denominaba "vil gusano" y "mujer ignorante y 
20) $[\ldots]$ aquel tiempo $[\ldots]$ era repartirse continuamente entre mí estas palabras: "Pobre, sola, despreciada y simple". [...] pobre de aquellos sentimientos, luces y afectos, y como entregada en manos de mi tibieza y temores; sola, porque escondió Nuestro Señor su presencia, mi confesor me faltó, Vuestra Paternidad se alejó más de esta ciudad, y aun en lo temporal experimenté esta soledad, porque se fue de mi compañía quien asistía a mis necesidades y enfermedades, y así volví a padecer en lo espiritual y temporal (pp. 131-132).

Sin embargo, a diferencia de estas mujeres (ver nota 12), en Francisca Josefa de Castillo la estrategia discursiva de humillarse queda implícitamente anulada en el momento en que, nuevamente, aparece en su discurso una comparación de su propia persona con Jesús, igual que sutilmente ha hecho con la Virgen, las santas, su madre y su sobrina (ver apartados respectivos):

21) Pues estando como he dicho, llegué un día a recibir a Nuestro Señor Sacramentado y me parece entendí llamarme "Hija de David", y Nuestro Señor "Esposa suya", dándome a entender muchas cosas que escribí entonces: que no despreciara mi alma, ni me tuviera por perdida, por padecer tantas y tales tentaciones (p. 250).

Para comprender esta alusión a Jesús, conviene recurrir al discurso neotestamentario en el que se le llama "Hijo de David" en numerosas ocasiones (La Santa Biblia, Mt 9:27, 12:23, 15:22, 20:30, 20:31, 21:9, 21:15; Mc 10:47, 10:48, 12:35; Lc 18:38, 18:39, 20:41), con lo que se le reconoce su papel mesiánico en la historia. Cabe además resaltar que, al poner este sintagma sobre sí misma en boca de Jesús, lo convierte en irrefutable, pues Dios-Jesús es el único ser por encima del varón dentro de la jerarquía marcada por la cosmovisión cristiana $\mathrm{y}$, por tanto, socioculturalmente autorizado para considerarla su igual (Fernández Martín, 2020).

pobre", con el objetivo último de desautorizarse para que el interlocutor evaluara el discurso per se y no de quien procedía (Bernabé Ubieta, 2016; Fernández Martín, 2018). La desautorización es una estrategia frecuente en textos de otras religiosas (Cortés Timoner, 2017; Fernández Martín, 2020).

Revista Cultura \& Religión Vol. XV, 2021 No 1 (enero-junio) 
En definitiva, todo el texto escrito por la clarisa es una hierofanía que representa metafóricamente la figura de Jesús como modelo de vida que inspira (especial, aunque no exclusivamente) el servicio religioso femenino, algo "prohibido" por la teología oficial y defendido por muchos hombres que, como se ha indicado (apartado 2.4), consideran que la mujer debe parecerse a María, no a Cristo (Ferrús Antón, 2008; Ferrús y Girona, 2009; Hollywood, 2004). Tal vez sea esta imitatio Christi una de las premisas simbólico-religiosas del feminismo de la igualdad (Stamile, 2020) que configuren, precisamente, la mayor reivindicación feminista de la franciscana, dentro de una cosmovisión católica de la que, por cuestiones socioculturales evidentes, no podía naturalmente escapar (Ferrús Antón, 2008; Noguerol, 2002).

\section{Interpretaciones del análisis a la luz del contexto sociocultural de su Vida}

Con la biografía de Francisca Josefa en mente (apartado 2), retomamos los dos elementos socioculturales que establecíamos en la introducción, sintetizables en la explotación interesada del cristianismo por parte de unos pocos para la configuración sociopolítica de la América colonial. Desde la perspectiva de la ideología de la Contrarreforma, pues, todo lo que escribe una religiosa como Francisca Josefa se ajusta formalmente al discurso que se espera de ella, de acuerdo con su estatus de género y de clase (este último privilegiado), como la autobiografía, sumamente eficaz para dar a conocer al mundo su verdadero pensamiento, bajo la apariencia de escribir por orden de un confesor, como se venía haciendo, históricamente, en las cuentas de conciencia o en las relaciones del espíritu (Arévalo Viveros, 2017; Ferrús Antón, 2008; Ferrús y Girona, 2009; Noguerol, 2002; Poutrin, 2018).

Sin embargo, si se profundiza en ciertos elementos de su texto, ella parece posicionarse como defensora de una espiritualidad puramente femenina, representada por las figuras de la Virgen María (apartado 2.1) y de determinadas santas (apartado 2.2). En primer lugar, entiende a la Virgen como madre perfecta y a la vez vulnerable mujer (ver citas 1 y 2 ), aceptando la 
paradójica idea de La perfecta casada de fray Luis de León (Ferrús y Girona, 2009), pero considerándola a la vez salvadora no solo porque interceda entre un supuesto poder superior y ella misma (“puerta de todo el bien”), sino porque, al considerarla "Nuestra Señora", ella misma es el poder superior, perteneciente a todos los creyentes, por equivalencia linguiística-funcional con "Señor”. En segundo lugar, la clarisa huye de la distinción entre mística y bruja, etiquetado típicamente patriarcal (Bechtel, 2001; Bernabé Ubieta, 2016) porque, para ella, el mensaje de las mujeres santas que menciona adquiere un profundo valor metafísico, pues todas están por encima de sí mismas, conectadas a través del tiempo gracias a una práctica religiosa común que las caracteriza (ver citas 4 y 6), más allá de toda clasificación terrenal (por antonomasia, patriarcal). En tercer lugar, todas sus biografías ofrecen una fuerte carga simbólica que, como diría sor Juana Inés (v. supra n. 4 o Respuesta, líneas 78-83), no hace falta mencionar explícitamente porque cobran significado por sí solas, pues se da por hecho que el lector va a saber interpretar, al hilo del texto bíblico compartido, lo que se pretende decir. En cuarto lugar, las alusiones a mujeres como Catalina de Siena y Teresa de Ávila conllevan también una fuerte identidad femenina, pues se construyen en el imaginario colectivo como féminas fuertes e independientes, especialmente cuando padecen las experiencias místicas que las liberan de las ataduras de este mundo (apartado 2.2). Finalmente, la santa a la que probablemente más admiración debe es Magdalena de Pazzi, a quien considera maestra, madre y reina (ver citas 5 y 6 ).

Asimismo, su madre es a sus ojos una gran devota digna de la santidad (apartado 2.3), que le supone un modélico ejemplo a seguir con reminiscencias de las místicas renacentistas y medievales, que culminan en una "disposición admirable" para recibir directamente a Dios (ver cita 8). Especularmente, el hecho de que considere explícitamente "madre" a varias santas, como Clara (p. 283) y Magdalena (apartado 2.3), permite la interpretación de la equivalencia funcional entre el ser santa y el ser $s u$ madre.

Cuando trata a las otras mujeres, las puramente humanas (apartado 2.4), por así decir, Francisca Josefa no las etiqueta ni siguiendo el patrón cultural de 
santas, brujas, putas y tontas, ni siguiendo el orden social establecido de criadas, indias, mestizas y mulatas, al menos por dos motivos. Por un lado, porque en su convento probablemente toda mujer religiosa stricto sensu perteneciera a su misma clase social, pues las mestizas, indias, mulatas y negras, así como cualquier otra mujer sin dote, no tenían derecho a profesar (Ferrús y Girona, 2009), ${ }^{13}$ como muestra el hecho de que muchas de las seglares que vivían en los conventos eran criadas o incluso esclavas (Martínez Cuesta, 1995). Por otro lado, porque para ella son personas de carne y hueso, cercanas, cuya distinción, primero, entre familiar (ver citas 9 y 10) y no familiar (ver citas 11-16) y, después, entre amiga (ver citas 14-16) y enemiga (ver citas 11-13), solo tiene sentido desde la ética del cuidado típicamente femenina (Valcárcel, 2010), que implica una preocupación por las personas de su alrededor, con las que convive a diario (ver citas 9-16). El punto de partida de su análisis y, a la vez, el destino de su autobiografía no pretende alcanzar los rasgos universalizadores que durante siglos han hecho equivalentes los conceptos de andrós y de ánthropos en una historia vista con ojos masculinos. Ella no impone un etiquetado a las mujeres en el que estas acaban reconociéndose, como tiende a hacerse en el patriarcado con colectivos "molestos" (Bernabé Ubieta, 2016); ella lo hace, simplemente, desde su yo personal, desde su propia experiencia vivida, para reconocimiento de sí misma y, si acaso, de su lector, pero no necesariamente con el afán de naturalizar los procesos sociales ni de reificar a las personas.

Y esto resulta ser así porque, a caballo entre este mundo terrenal y el otro mundo celestial, se encuentra ella misma (apartado 2.5), incrustada en la contradicción que implica la modestia del proceso escriturario de toda obra, requerida por su género y cuya ruptura ocasiona ser considerada maldita desde el principio de su vida (ver citas 18-20), y la necesidad de expresarse como realmente siente (ver cita 21), a modo de redención solo posible mediante el

${ }^{13}$ Sor Teresa Chikaba (¿1676?-1748), la primera monja negra que entró en un convento español (Maeso, 2004), es precisamente la (primera) excepción que confirma la regla.

Revista Cultura \& Religión Vol. XV, 2021 No 1 (enero-junio) femenina en la vida de sor Francisca de la Concepción. Revista Cultura \& Religión, $15(1), 108-143$ 
mismo proceso de escritura (Arévalo Viveros, 2017; Ferrús Antón, 2008; Noguerol, 2002).

Vemos entonces cómo, en el texto de la clarisa, lo social se fusiona con lo cultural no al tomar forma en un aprovechamiento de la fe cristiana para beneficiarse de un orden jerárquico supuestamente natural, como se ha hecho desde el patriarcado y demuestra fehacientemente la conquista de América (Chocano Mena, 2000; Pérez Herrero, 2011), sino al configurarse en un disfrute interior de la experiencia religiosa que permite una comprensión dinámica del mismo hecho de ser mujer y, si acaso, una clasificación basada en la proximidad que cada persona mantiene con ella (cercana vs. lejana), traducible en un continuum entre "amiga" y "enemiga" (apartado 2.4). No ha de extrañar, entonces, que emplee este mismo sustantivo, "enemigo", ${ }^{14}$ para referirse constantemente al demonio (ver citas 17 y 20), en un alarde de definir con claridad de quién debe fiarse y de quién no.

Lo característico de esta clasificación en términos de mayor o menor proximidad emocional es que, basada en una autodefensa que le permite, a su vez, generar pautas de conducta con respecto a la toma de decisiones sociopolíticas (ver cita 16) en la gestión del convento (recuérdese que fue abadesa durante varios años, de forma alterna, y brilló por su habilidad gestora), iguala a todas las mujeres, sean celestiales o terrenales, pues les aplica dicha taxonomía según las considera más o menos cercanas en función, por un lado, de la empatía que sienta con cada una de ellas lo que, por otro lado y por extensión semántica, implica su incorporación discursiva a la genealogía familiar. Es decir, el hecho de que emplee términos como "madre" para referirse a determinadas santas o a la Virgen (apartados 2.1, 2.2) está en consonancia con la necesidad de sentirlas próximas emocionalmente y, por tanto, incorporarlas a la lista de personas en las que necesita confiar.

\footnotetext{
${ }^{14}$ Nótese que en su versión masculina aparece registrado en más de un centenar de ocasiones en su Vida, frente a "enemiga", que solo aparece en lo aquí expuesto como cita 7. A este respecto, resulta altamente interesante subrayar que la misma palabra "enemigo" (en masculino) es uno de los términos que se emplean aún hoy en determinadas zonas, al menos, de Hispanoamérica, para denominar al demonio (Cantón, 2009).
}

Revista Cultura \& Religión Vol. XV, 2021 № 1 (enero-junio) 
La diferencia con el etiquetado de corte patriarcal se encuentra en que esta imagen de la (otra) mujer permite entender la complejidad de las relaciones políticas que se gestaban en el convento (Chocano Mena, 2000). Mucho más allá de análisis simplistas que reducen todo su quehacer al bordar y al orar, la vida conventual se traducía así en un espacio con reglas socioculturales propias cuyas principales diferencias con respecto a las del exterior se encuentran, por un lado, en la característica de ser dinámicas, no esencialistas, pues aquella monja que un día era amiga podía dejar de serlo al día siguiente; y, por otro lado, en la opción de no hacerse públicas y, por tanto, estigmatizadoras, pues parten de la experiencia femenina propia y no salen de ella, por lo que no se emplean para excluir a unos colectivos frente a otros sino que, simplemente, sirven como guías de conducta autopropuestas.

Recuérdese que, como hemos indicado (apartado 2), la necesidad de etiquetar a la alteridad viene del miedo a perder el poder sobre ella. Por tanto, igual que, con el paso del tiempo, se comienza a difundir una imagen negativa de los nuevos inmigrantes procedentes de la Península (herederos de los vicios de ambas "razas", "ilegítimos", con sangre "contaminada"), convertidos en mestizos sociológicos (porque conformaban un colectivo a caballo entre los indígenas y los colonos), pues la pirámide social ya no podía absorberlos y, por ello, amenazaban con eliminar los privilegios de los encomenderos (Martínez Shaw y Alfonso Mola, 2008; Pérez Herrero, 2011), las mujeres de toda clase y condición siempre constituían una amenaza para el poder patriarcal, especialmente si eran mínimamente letradas y, por tanto, capaces de construir discursos convincentes sin ayuda de ningún varón. A las estrategias discursivas que las mujeres desarrollaban para transformar el etiquetado que les venía impuesto en algo menos perjudicial, como la autoestigmatización, el autodesprecio y la (des)autorización (Arévalo Viveros, 2017; Bernabé Ubieta, 2016; Cortés Timoner, 2017; Lewandowska, 2019), cabe ahora añadir lo que podría llamarse la "etiquetación dinámica por proximidad emocional", eficaz, al menos en el caso de Francisca Josefa de Castillo, para clasificar a aquellas

Revista Cultura \& Religión Vol. XV, 2021 No 1 (enero-junio) femenina en la vida de sor Francisca de la Concepción. Revista Cultura \& Religión, $15(1), 108-143$ 
personas con las que se comparte la vida de manera habitual siguiendo el inevitablemente subjetivo criterio de la confianza.

\section{Reflexiones finales}

El objetivo del trabajo es demostrar la existencia de un discurso feminista anterior a la Revolución Francesa que, naturalmente, vendría expresado de forma tácita y empleando estrategias discursivas como la desautorización o la autoestigmatización. Aunque falta mucho por investigar al respecto, pues no ha habido demasiado interés en estudiar la imagen que de la mujer tiene la propia mujer, cabe concluir que, en el caso analizado de su Vida, la clarisa Francisca Josefa de la Concepción muestra una imagen femenina muy diferente a la que se mantiene en el patriarcado.

Así, mediante lo que se puede denominar un "fenómeno lingüístico de etiquetación dinámica por proximidad emocional", ella no clasifica a las mujeres que se encuentran a su alrededor en función de su comportamiento religioso (cultural) o del lugar que ocupen en la escala jerárquica (social), sino que emplea un criterio basado en la confianza, claramente subjetivo, que le sirve para tomar decisiones en el futuro, en lo que adopta una fusión sociocultural que efectúa en su estricto provecho, a modo de autodefensa. En todo caso, se trata de un criterio dinámico y no estigmatizador, pues permite entender las relaciones socioculturales entre las personas desde una perspectiva sistémica-compleja.

Esta visión de las mujeres, ofrecida de forma velada por una criolla aún en plena época colonial, puede encontrarse, salvando naturalmente las distancias, a caballo entre el feminismo de la diferencia y el feminismo de la igualdad. En tanto la clasificación de todas las mujeres se guía por el mismo criterio, el de la confianza, sin embargo es, a su vez, diferente al que los hombres usan para clasificarlas a ellas (y ellas mismas cuando se mantienen dentro del sistema simbólico patriarcal); se trata de un (proto)feminismo de la

Revista Cultura \& Religión Vol. XV, 2021 No 1 (enero-junio) 
diferencia, en el que ella defiende el derecho de las mujeres a etiquetarse a sí mismas como ellas consideren y no como les venga dado de fuera.

A la vez, el (proto)feminismo de la igualdad viene de la mano de la vindicación de la mujer religiosa a parecerse a Cristo y no necesariamente (o no exclusivamente) a María. Toda la obra se puede leer en clave de calvario, por supuesto, por la importancia del dolor y el sufrimiento que en ella se muestra. Pero este hecho no significa que la imitación deba quedarse en la experiencia mística: la imitatio Christi supone un deseo de alcanzar en la tierra el reconocimiento universal e inclusivo que él defendió y que ha sido tergiversado y manipulado por el poder eclesiástico (masculino) durante siglos.

En definitiva, si el (proto)feminismo de la diferencia alude a aspectos puramente sociales y el (proto)feminismo de la igualdad refiere a aspectos puramente culturales, cabe entonces concluir que en la vida de Francisca de Castillo lo sociocultural, como se ha dejado entrever, cobra sentido desde la experiencia personal, como principal herramienta para la relación con los demás, algo que poco tiene que ver con la misma configuración de lo sociocultural desde la visión masculina de su mundo. Estudiar desde esta perspectiva más textos de mujeres religiosas sin duda alguna permitiría aplicar a otros contextos lo analizado aquí en la autobiografía de una escritora que se ha ganado a pulso convertirse en universal.

\section{Referencias bibliográficas}

Amorós Puente, C. (2008). El feminismo como proyecto filosófico-político. En F. Quesada (ed.), Ciudad y ciudadanía. Senderos contemporáneos de la Filosofía Política (pp. 64-87). Madrid: Trotta.

Amorós, C. y De Miguel Álvarez, A. (2007). Introducción: Teoría feminista y movimientos feministas. En C. Amorós y A. de Miguel (eds.), Teoría feminista: de la Ilustración a la globalización. De la Ilustración al segundo sexo (1) (pp. 13-90). Madrid: Minerva.

Revista Cultura \& Religión Vol. XV, 2021 № 1 (enero-junio) 
Arévalo Viveros, D. (2017). Conventualización de la escritura en las Vidas de Santa Teresa de Jesús y Francisca Josefa de Castillo. Literatura: Teoría, Historia y Crítica 19(1), 197-224. Recuperado de http://dx.doi.org/10.15446/lthc.v19n1.60865

Beattie, T. (2004). Redeeming Mary: the potential of Marian symbolism for feminist philosophy of religion. En P. S. Anderson y B. Clack (eds.), Feminist Philosophy of Religion. Critical Readings (pp. 107-122). Nueva York/Oxon: Routledge.

Bechtel, G. (2001). Las cuatro mujeres de Dios: la puta, la bruja, la santa y la tonta. Barcelona: Ediciones B.

Bernabé Ubieta, C. (2016). De místicas, brujas y feministas cristianas. En S. Bara Bancel (ed.), Mujeres, mística y política. La experiencia de Dios que implica y complica (pp. 253-267). Navarra: Verbo Divino.

Bourdieu, P. (2008). ¿Qué significa hablar? Economía de los intercambios lingüísticos. Madrid: Akal.

Brescia, P. A. J. (1998). El ‘crimen' y el castigo: la Carta Atenagórica, de Sor Juana Inés de la Cruz. Caravelle, 70(1), 73-96. Recuperado de http://www.persee.fr/doc/carav_1147-6753_1998_num_70_1_2776

Bueno-Gómez, N. (2018). Self-management and Narrativity in Teresa of Avila's work. Life Writing, 15(3), 305-320. doi: 10.1080/14484528.2018.1475001

Bueno-Gómez, N. (2019). «I Desire to Suffer, Lord, because Thou didst Suffer»: Teresa of Avila on Suffering. Hypatia. A Journal of Feminist Philospohy. 34(4), 755-776. Recuperado de https://doi.org/10.1111/hypa.12488

Cantón, M. (2009). Simbólica y política del diablo pentecostal. Revista Cultura\&Religión, 3(1), 81-95. Recuperado de https://www.revistaculturayreligion.cl/index.php/revistaculturayreligion/ article/view/171/160

Chocano Mena, M. (2000). La América colonial (1492-1763). Cultura y vida cotidiana. Madrid: Síntesis. 
Cortés Timoner, $\mathrm{M}^{\mathrm{a}}$ M. (2017). Estrategias de autorización en el discurso espiritual de Teresa de Cartagena y Teresa de Jesús. Cahiers d'Études des Cultures Ibériques et Latino-américaines, (3), 9-26. Recuperado de http://cecil-univ.eu/wp-content/uploads/2017/12/c3_mct_9_25.pdf

Coseriu, E. (2007). Lingüistica del texto. Introducción a la hermenéutica del sentido. Madrid: Arco/Libros.

De Jesús, T. (2014). El libro de la vida (ed. Fidel Sebastián Mediavilla). Madrid España: Espasa/RAE.

De Jesús, T. (1577-2015). Las moradas del castillo interior (ed. por Dámaso Chinarro). Madrid: Biblioteca nueva.

De la Cruz, J. I. ([1692] 1994). Obra selecta. Tomo II. Caracas: Biblioteca Ayacucho.

Díaz de Rada, Á. (2010). Cultura, antropología y otras tonterías. Madrid: Trotta.

Fernández Martín, P. (2018). "Del nivel interpersonal al nivel morfosintáctico en algunas cartas de sor María de Jesús de Ágreda". Estudios Humanísticos. Filología, 40, 41-69. Visitado el 10 de noviembre de 2020. Recuperado de http://revpubli.unileon.es/ojs/index.php/ EEHHFilologia/article/view/5449/4335

Fernández Martín, P. (2020). “Conocimiento, poder y religión: hacia una consideración de la mística teresiana como discurso teológicofilosófico". Investigaciones Feministas 11(1), pp. 155-165. Visitado el 14 de noviembre de 2020. Recuperado de http://dx.doi.org/infe.65806

Ferrús Antón, B. (2008). "Mayor gloria de Dios es que lo sea una mujer... Sor María de Jesús de Ágreda y sor Francisca de la Concepción del Castillo (sobre la escritura conventual en los siglos XVI y XVII)". Revista de Literatura, 70(139), 31-46. Visitado el 16 de noviembre de 2020. Recuperado de https://dialnet.unirioja.es/servlet/articulo? codigo $=2674232$ \&orden $=162088 \&$ info $=$ link 
Ferrús Antón, B. y Girona Fibla, N. (eds.) (2009). Estudio preliminar. En B. Ferrús y N Girona (eds.), Vida de Sor Francisca Josefa de Castillo (pp. 7-80). Madrid/Frankfurt: Iberoamericana/Vervuert.

Fogelman, P. A. (2014). El cuerpo de la Virgen: discursos teológicos y representaciones históricas del cuerpo y la muerte de María. Revista Cultura \& Religión, 8(2), 197-231. Recuperado de https://www.revistaculturayreligion.cl/index.php/revistaculturayreligion/ article/view/556/469

Forcades i Vila, T. (2011). La teología feminista en la historia. Barcelona: Fragmenta.

Fraijó, M. (1998). A vueltas con la religión. Navarra: Verbo Divino.

Frankenberry, N. (2004). Feminist approaches. En P. S. Anderson y B, Clack (eds.), Feminist Philosophy of Religion. Critical Readings (pp. 3-27). Nueva York/Oxon: Routledge.

Galaz-Vivar Welden, A. (1990). Francisca Josefa de Castillo. Una mística del Nuevo Mundo. Thesaurus. Boletín del instituto Caro y Cuervo, 45(1), 149-161.

González Marín, C. (2003). La doncella de hierro y la odalisca: metafísica de una imagen femenina. Feminismo/s, (2), 15-24. doi: http://dx.doi.org/10.14198/fem.2003.2.02

Granados Valdéz, J. (2020). Estética de la alegría del sacrificio. Anacronismo de la modernidad. Revista Cultura \& Religión, 14(1), 13-25. Recuperado de https://www.revistaculturayreligion.cl/index.php/ revistaculturayreligion/article/view/839

Herrera, C. (2017). Praises and prayers to Mary in the writings of Francisca Josefa de Castillo y Guevara. Caliope: Journal of the Society for Renaissance and Baroque Hispanic Society, 22(2), 165-189.

Hincapié, L. (2007). Virgen, ángel, flor y debilidad: paradigmas de la imagen de la mujer en la literatura colombiana de finales del siglo XIX. Tabula Rasa, (6), 287-307. Recuperado de https://www.redalyc.org/ articulo.oa? $\mathrm{id}=39600612$ 
Hollywood, A. (2004). Practice, belief and feminist philosophy of religion. En P. S. Anderson y B. Clack (eds.), Feminist Philosophy of Religion. Critical Readings (pp. 225-240). Nueva York/Oxon: Routledge.

Kuper, A. (2001). Cultura. La versión de los antropólogos. Barcelona: Paidós. Lagarde y de los Ríos, M. (2003). Los cautiverios de las mujeres: madresposas, monjas, putas, presas y locas. México: Universidad Nacional Autónoma de México.

La Santa Biblia (1991). Madrid: Ediciones Paulinas.

Lewandowska, J. (2013). (Des)alienar las voces femeninas del convento: "la celda propia" de Sor Marcela de San Félix. Itinerarios. Revista de Estudios Lingüísticos, Literarios, Históricos y Antropológicos, 18, 1134. Recuperado de http://itinerarios.uw.edu.pl/desalienar-las-vocesfemeninas-del-convento-la-celda-propia-de-sor-marcela-de-san-felix

Lewandowska, J. (2019). Escritoras monjas: autoridad y autoría en la escritura conventual femenina de los Siglos de Oro. Madrid/Frankfurt: Iberoamericana/Vervuert.

Lewellen, T. C. (2003). Introducción a la antropología política. Barcelona: Bellaterra.

Llamedo González, J. J. (2018). Teología de Teresa de Jesús. Doctora de la Iglesia. Una visión sistematizada. Madrid: San Pablo.

Maeso, M. E. (2004). Sor Teresa Chikaba. Princesa, esclava y monja. Salamanca: San Esteban.

Manero Sorolla, M. P. (1992). Diálogos de carmelitas: Libro de Recreaciones de María de San José. En A, Vilanova Andreu (ed.), Actas del X Congreso de la Asociación Internacional de Hispanistas: Barcelona 21 26 de agosto de 1989, vol. 1. (pp. 501-516). Barcelona: Promociones y Publicaciones Universitarias.

Martín Velasco, J. (2006). Introducción a la fenomenología de la religión. Madrid: Trotta.

Martínez Cano, S. (2016). Recuperar la voz, ejercitar la expresión, liberar la pasión por Dios. En S. Bara Bancel (ed.), Mujeres, mística y política. La

Revista Cultura \& Religión Vol. XV, 2021 № 1 (enero-junio) 140 femenina en la vida de sor Francisca de la Concepción. Revista Cultura \& Religión, $15(1), 108-143$ 
experiencia de Dios que implica y complica (pp. 231-267). Navarra: Verbo Divino.

Martínez Cuesta, Á. (1995). Las monjas en la América colonial. 1530-1824.

Thesaurus: Boletín del Instituto Caro y Cuervo, 50(1-3), 572-626.

Martínez Shaw, C. y Alfonso Mola, M. (2008). Europa y los nuevos mundos en los siglos XV-XVIII. Madrid: Síntesis.

Mazariegos Herrera, H. M. C. (2019). Mujeres metodistas en León, Guanajuato-México: liderazgos en movimiento. Revista Cultura \& Religión, 13(1), 24-44. Recuperado de https://www.revistaculturayreligion.cl/index.php/revistaculturayreligion/ article/view/850

Noguerol, F. (2002). Mujer y escritura en la época de sor Juana Inés de la Cruz. América Latina Hoy, 30, 179-202. Recuperado de http://campus.usal.es/ revistas_trabajo/index.php/11302887/article/view/2357/2405

Oviedo, J. M. (2012). Historia de la literatura hispanoamericana. 1. De los orígenes a la emancipación. Madrid: Alianza.

Pardo Bazán, E. ([1886] 2003). Los pazos de Ulloa. Madrid: Cátedra.

Pérez Herrero, P. (2011). La América colonial (1492-1763). Política y sociedad. Madrid: Síntesis.

Poutrin, I. (2018). Autobiografías. En N. Baranda Leturio y A. J. Cruz (eds.), Las escritoras españolas en la Edad Moderna. Historia y guía para la investigación (pp. 117-132). Madrid: UNED.

Puleo, A. (2008). Los derechos humanos, un legado de la modernidad. En F. Quesada (ed.), Ciudad y ciudadanía. Senderos contemporáneos de la filosofía política (pp. 185-204). Madrid: Trotta.

Ramón, L. (2010). Queremos el pan y las rosas. Emancipación de las mujeres y cristianismo. Madrid: HOAC.

Robles Rivera, S. (2018). El misterio trinitario en la teología feminista. Reflexiones para una antropología inclusiva. Palabra y Razón. Revista 
de Teología y Filosofía, (13), 63-90. Recuperado de http://revistapyr.ucm.cl/article/view/248

Ródenas Utray, P. (2008). Problemas de legitimación del poder. En F. Quesada (ed.), Ciudad y ciudadanía. Senderos contemporáneos de la filosofía política (pp. 141-166). Madrid. Trotta.

Sánchez Díaz Aldagalán, C. (2019). María de la O Lejárraga: la imagen de la mujer en su literatura. Logroño: Instituto de Estudios Riojanos.

Servén Díez, Mª C. (2008). Canon literario, educación y escritura femenina. Ocnos: Revista de Estudios sobre Lectura, (4), noviembre, 7-20. Recuperado de https://revista.uclm.es/index.php/ocnos/article/view/ ocnos_2008.04.01/175

Stamile, N. (2020). Igualdad, diferencia y teoría feminista. Eunomía. Revista en Cultura de la Legalidad, (18), abril, 9-28. Recuperado de https://doi.org/10.20318/eunomia.2020.5261

Steffanell, A. (2010). Sor Francisca Josefa de Castillo (1671-1742): una «rara avis» en el canon de la literatura colombiana fundacional. Cuadernos de Literatura, 14(28), 100-129. Recuperado de https://www.redalyc.org/ pdf/4398/439843026006.pdf

Tapia-Adler, A. M. (2007). Concepción de la muerte en el judaísmo. Revista Cultura \& Religión, 1(2), 16-30. Recuperado de https://www.revistaculturayreligion.cl/index.php/revistaculturayreligion/ article/view/194

Valcárcel, A. (2010). Ética y feminismo. En C. Gómez y J. Muguerza (eds.), $L a$ aventura de la moralidad (paradigmas, fronteras y problemas de la ética) (pp. 464-479). Madrid: Alianza.

Verschueren, J. (2013). Ideology in Language Use. Cambridge: Cambridge University Press.

Walton, H (2004). Women writing the divine. En P. S. Anderson y B. Clack (eds), Feminist Philosophy of Religion. Critical Readings (pp. 123-135). Nueva York/Oxon: Routledge. 
* Este trabajo se enmarca dentro del proyecto I+D del Ministerio de Economía y Competitividad, titulado "Procesos de gramaticalización en la historia del español (V): gramaticalización, lexicalización y análisis del discurso desde una perspectiva histórica" (FFI2015-64080), dirigido por el Dr. Francisco Javier Herrero Ruiz de Loizaga, de la Universidad Complutense de Madrid.

** Doctora en Lengua Española y sus Literaturas, Universidad Complutense de Madrid. Licenciada en Antropología Social y Cultural y graduada en Filosofía, Universidad Nacional de Educación a Distancia (España). Profesora del Departamento de Filologías y su Didáctica, Facultad de Formación de Profesorado y Educación de la Universidad Autónoma de Madrid. patricia.fernandez01@uam.es 